\title{
A new, mesophotic Coryphopterus goby (Teleostei, Gobiidae) from the southern Caribbean, with comments on relationships and depth distributions within the genus
}

\author{
Carole C. Baldwin', D. Ross Robertson ${ }^{2}$ \\ I Department of Vertebrate Zoology, National Museum of Natural History, Smithsonian Institution, Washington, \\ DC 205602 Smithsonian Tropical Research Institute, Balboa, Republic of Panamá \\ Corresponding author: Carole C. Baldwin (baldwinc@si.edu)
}

Academic editor: N. Bogutskaya | Received 15 May 2015 | Accepted 28 June 2015 | Published 17 July 2015

http://zoobank.org/FDE184B5-77F2-488B-BAOC-1FF9BE5180E1

Citation: Baldwin CC, Robertson DR (2015) A new, mesophotic Coryphopterus goby (Teleostei, Gobiidae) from the southern Caribbean, with comments on relationships and depth distributions within the genus. ZooKeys 513: $123-142$. doi: $10.3897 /$ zookeys. 513.9998

\begin{abstract}
A new species of western Atlantic Coryphopterus is described from mesophotic depths off Curaçao, southern Caribbean. Coryphopterus curasub sp. n., is similar to $C$. dicrus in, among other features, having two prominent pigment spots of roughly equal intensity on the pectoral-fin base, the pelvic fins fused to form a disk, and no pelvic frenum. The two species can be differentiated by body depth (shallower in C. curasub at origin of dorsal fin and caudal peduncle); differences in the pigmentation on the head, trunk, and basicaudal region; and usually by total number of rays (spinous plus soft) in the second dorsal fin (10-11, usually 11, in C. curasub, 10 in C. dicrus). Coryphopterus curasub differs from other Coryphopterus species that have a prominent pigment spot on the lower portion of the pectoral-fin base (C. punctipectophorus and $C$. venezuelae) in, among other features, lacking a pelvic frenum. Coryphopterus curasub was collected between 70 and $80 \mathrm{~m}$, the deepest depth range known for the genus. Collections of $C$. venezuelae at depths of 65-69 m extend the depth range of that species by approximately $50 \mathrm{~m}$. Mitochondrial cytochrome c oxidase subunit I (COI) data corroborate the recognition of C. curasub as a distinct species but do not rigorously resolve its relationships within the genus. A revised key to the western Atlantic species of Coryphopterus is presented.
\end{abstract}

\section{Keywords}

Coryphopterus curasub, Coryphopterus dicrus, submersible, Substation Curaçao, Deep Reef Observation Project (DROP), DNA barcoding, phylogeny

Copyright Carole C. Baldwin, D. Ross Robertson. This is an open access article distributed under the terms of the Creative Commons Attribution License (CC BY 4.0), which permits unrestricted use, distribution, and reproduction in any medium, provided the original author and source are credited. 


\section{Introduction}

Coryphopterus gobies live in mostly shallow warm waters of the western Atlantic and eastern Pacific Oceans, dwelling on sand around coral and rocky reefs or hovering above or perching on reef structures. Twelve species are known from the western Atlantic and one from the eastern Pacific (Böhlke and Robins 1960, 1962; Thacker and Cole 2002; Victor 2007; Baldwin et al. 2009). Most Coryphopterus species inhabit depths $<40$ $\mathrm{m}$, but $C$. hyalinus Böhlke \& Robins has been recorded to $52 \mathrm{~m}$; C. eidolon Böhlke \& Robins and $C$. thrix Böhlke \& Robins to $54 \mathrm{~m}$; $C$. dicrus Böhlke \& Robins to $56 \mathrm{~m}$; $C$. lipernes Böhlke and Robins to $60 \mathrm{~m}$; C. glaucofraenum Gill to $61 \mathrm{~m}$; and C. personatus (Jordan \& Thompson) to $70 \mathrm{~m}$ (Böhlke and Robins 1960, 1962; Thacker and Cole 2002; Feitoza et al. 2005, Robertson and Van Tassell 2015). Published depth data for C. glaucofraenum, however, as well as that for C. tortugae (Jordan) $(5-32 \mathrm{~m})$ and $C$. venezuelae Cervigón (1-20 m), must be interpreted cautiously because of historical confusion about the taxonomy of this group, as should those of $C$. hyalinus and $C$. personatus for the same reason (Baldwin et al. 2009). Recent submersible diving to $300 \mathrm{~m}$ off Curaçao in the southern Caribbean as part of the Smithsonian Institution's Deep Reef Observation Project (DROP) resulted in the collection of three specimens of C. venezuelae at 65-69 m and four specimens of an unidentified Coryphopterus at $70-80 \mathrm{~m}$. We describe the specimens from $70-80 \mathrm{~m}$ as a new species and comment on its relationships within the genus.

Thacker and Cole (2002) investigated species relationships within Coryphopterus based on morphology and one mitochondrial gene (ND2). Their phylogeny suggests that Coryphopterus is restricted to the western Atlantic and eastern Pacific and that the Indo-Pacific genus Fusigobius, which Randall (1995) synonymized with Coryphopterus, is distinct. Based on study of the western Atlantic Lophogobius cyprinoides, Thacker and Cole (2002) and Thacker and Roje (2011) hypothesized that Coryphopterus is more closely related to Lophogobius than it is to Fusigobius. The eastern Pacific C. nicholsii (Bean), which is sister to Lophogobius + Coryphopterus in the phylogenies of Thacker and Cole (2002) and Thacker and Roje (2011), has been re-relegated to the monotypic genus Rhinogobiops Hubbs (Thacker 2011, Van Tassell 2011).

A new western Atlantic species, Coryphopterus kuna Victor, was described in 2007 but not included in the molecular phylogeny of Thacker and Roje (2011). Further, neither $C$. tortugae nor $C$. venezuelae was included in previous phylogenetic work, even though both appear to be valid Coryphopterus species. Although Longley and Hildebrand (1941) and Böhlke and Robins (1960) considered C. tortugae (Jordan) to be a synonym of C. glaucofraenum, Garzón-Ferreira and Acero (1990) redescribed it as valid. Victor (2008) concurred and also described a variant of $C$. tortugae as new species, C. bol. Based on an integrative molecular and morphological analysis, Baldwin et al. (2009) also recognized $C$. tortugae as valid but relegated $C$. bol to the synonymy of $C$. venezuelae. In addition to the new species described here, tissue samples of all known Coryphopterus species except the Gulf of Mexico species C. punctipectophorus Springer are now available and were incorporated into the genetic analyses conducted 
in this study. As noted by Baldwin et al. (2009), Thacker and Cole's (2002) DNA sequence from Belize previously thought to be from C. punctipectophorus (GenBank Accession No. AF391396) is actually from $C$. dicrus.

\section{Materials and methods}

Four specimens of the new species and three of $C$. venezuelae were collected using Substation Curaçao's (http://www.substation-Curacao.com) manned submersible Curasub. The sub has two flexible, hydraulic arms, one of which is equipped with a quinaldine-ejection system and the other with a suction hose. Anesthetized fish specimens were captured with the suction hose, which empties into a vented plexiglass cylinder attached to the outside of the sub. At the surface, the specimens were photographed, tissue sampled, and preserved. Preserved specimens were later photographed to document preserved pigment pattern and X-rayed with a digital radiography system. Counts and measurements follow Randall (2001). Format for dorsal-fin formula follows Birdsong et al. (1988). Head pore terminology follows Akihito et al. (1988). Measurements were made weeks to months after preservation and were taken to the nearest $0.1 \mathrm{~mm}$ with digital calipers or an ocular micrometer fitted into a Zeiss stereomicroscope.

Tissue samples for DNA Barcoding were stored in saturated salt-DMSO (dimethyl sulfoxide) buffer (Seutin et al. 1991). DNA extraction, PCR, sequencing cytochrome c oxidase subunit I (COI), and editing COI sequences were performed as outlined by Weigt et al. (2012a). A neighbor-joining tree (Saitou and Nei 1987) was generated using PAUP*4.1 (Swofford 2002) on an analysis of Kimura two-parameter distances (Kimura 1980). The neighbor-joining analysis reveals genetic distances in COI among individuals and clusters them into genetically distinct lineages, which, in teleost fishes, correspond well with species (e.g. Baldwin and Weigt 2012, Weigt et al. 2012b). Interspecific phylogenetic relationships were hypothesized for Coryphopterus based on maximum parsimony analysis of the COI sequences using heuristic searches in PAUP*4.1 (Swofford 2002). Characters were equally weighted and left unordered. The resulting equally parsimonious trees were summarized using the strict consensus method, and nodal support was estimated from 1,000 replicates of the bootstrap, utilizing random addition sequence and TBR branch swapping (Swofford 2002). The outgroup for the neighbor-joining analysis was a species of Fusigobius, a basal genus in the crested goby group that includes Coryphopterus, Lophogobius, and Rhinogobiops (Thacker and Roje 2011). Outgroups for the parsimony analysis were Fusigobius and Rhinogobiops.

GenSeq nomenclature (Chakrabarty et al. 2013) and GenBank accession numbers for DNA sequences derived in this study are presented along with museum catalog numbers for voucher specimens in the Appendix. GenBank accession numbers for Coryphopterus sequences included in the analyses that were published by Baldwin et al. (2009) are GQ367306-GQ367475, and those for Lophogobius cyprinoides sequences published by Weigt et al. (2012b) are JQ840574.1 and JQ842196.1. GenBank accession numbers for Fusigobius duospilus and Rhinogobiops nicholsii are JX462852 and HQ909488, respectively. 


\section{Results}

Coryphopterus curasub sp. $\mathrm{n}$.

http://zoobank.org/5C60A7B0-58D9-4896-81EF-A0D1DD28873D

Yellow-spotted sand goby

Figs $1-2$

Type locality. Curaçao, southern Caribbean

Holotype. USNM 406373, Smithsonian DNA number CUR 11373, $33.3 \mathrm{~mm}$ SL, female, Curasub submersible, sta. 11-05, southern Caribbean, Curaçao, east of downline off Substation Curaçao dock, near $12^{\circ} 05.069^{\prime} \mathrm{N}, 68^{\circ} 53.886^{\prime} \mathrm{W}, 80 \mathrm{~m}$, quinaldine, 30 May 2011, D. R. Robertson, B. Brandt, A Schrier, K. Stewart.

Paratypes. USNM 430037, CUR 13302, 30.0 mm SL, male, Curasub submersible, sta. 13-29, southern Caribbean, Curaçao, east of downline off Substation Curaçao dock, near $12^{\circ} 05.069^{\prime} \mathrm{N}, 68^{\circ} 53.886^{\prime} \mathrm{W}, 70-72 \mathrm{~m}$, quinaldine, 30 October 2013, C. C. Baldwin, D. R. Robertson, B. Brandt, C. Castillo, L. Ybarrondo. USNM 431328, CUR 14003, 31.0 mm SL, male, Curasub submersible, sta. 14-01, southern Caribbean, Curaçao, east of downline off Substation Curaçao dock, near $12^{\circ} 05.069^{\prime} \mathrm{N}$, 68 53.886'W, 73 m, quinaldine, 17 March 2014, C. C. Baldwin, D. R. Robertson, B. Brandt, C. Castillo, H. Reichardt. USNM 430019, CUR 13303, 17.5 mm SL, immature (same collection locality as USNM 430037), cleared and stained.

Generic assignment. The combination of six spines in the first dorsal fin, fewer than 20 rays in the second dorsal fin, pelvic fin with one spine and five soft rays, head pores present, no free pectoral-fin rays, no scales on top of head, and no prominent crest on top of head anteriorly from first dorsal fin support the placement of C. curasub in the genus Coryphopterus (Murdy 2002).

Diagnosis. A species of Coryphopterus distinguishable from its congeners by the following combination of characters: total second dorsal-fin rays (spinous plus soft) 10-11, usually 11; total anal-fin rays (spinous plus soft) 10; pectoral-fin rays 19-20; pelvic fins united; no pelvic frenum; pectoral-fin base with two prominent dark spots (yellow with dark spotting in life) of roughly equal intensity, one on dorsal portion of fin base and one on ventral part; no distinct black blotch behind orbit above opercle; no dark triangular blotch immediately behind middle of orbit; blotches of pigment on trunk mostly yellow; few melanophores and yellow dots interspersed among yellow blotches of pigment on trunk; no black ring of pigment surrounding anus; dark triangular blotch variously developed beneath anteroventral corner of orbit; basicaudal blotch cross-shaped, with prominent anterior projection; and two yellow/orange blotches on base of caudal fin situated immediately behind basicaudal blotch.

Description. Dorsal-fin rays VI + I, 9-10 (9 in one paratype, 10 in other specimens), total second dorsal-fin rays 10 or 11 (10 in one paratype, 11 in other specimens); anal-fin rays I, 9; all soft dorsal- and anal-fin rays branched. Pectoral-fin rays 19, 19 (paratypes) or 20, 20 (holotype); all pectoral rays branched except splint-like uppermost and lowermost rays. Pelvic-fin rays I, 5; all soft rays branched; fins unit- 

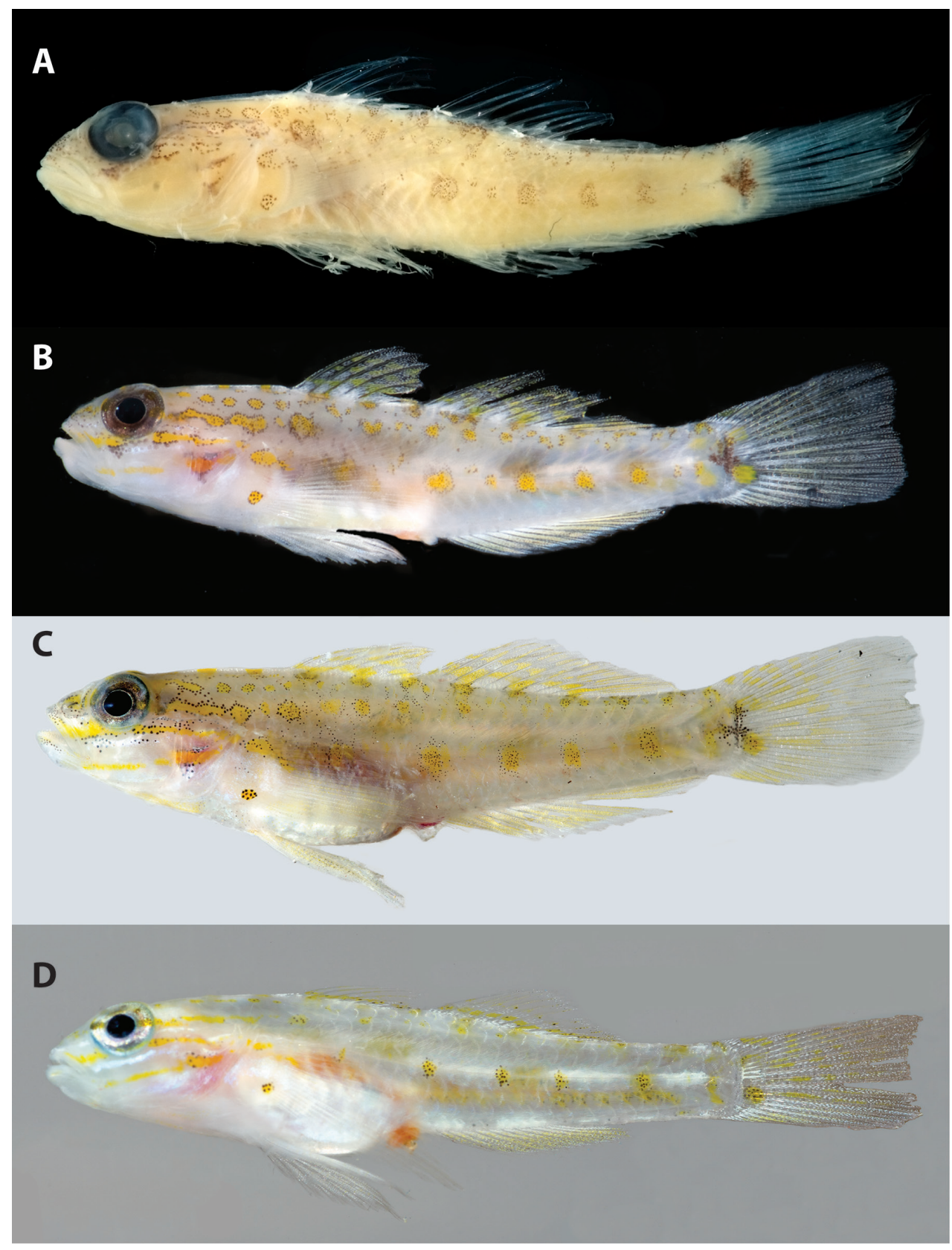

Figure I. Coryphopterus curasub sp. n., type specimens: A, B USNM 406373, holotype, Smithsonian DNA number CUR 11373, $33.3 \mathrm{~mm}$ SL, female - after preservation (A) and before preservation (B) C USNM 431328, Paratype, CUR 14003, 31.0 mm SL, male, before preservation D USNM 430019, Paratype, CUR 13303, $17.5 \mathrm{~mm} \mathrm{SL}$, immature, before preservation and clearing and staining. Note that the dark color on the posterior portion of the caudal fin is an artifact of flash photography and does not reflect the existence of dark pigment. Photos by Ian Silver-Gorges (A) and D. R. Robertson and C. C. Baldwin (B-D). 
ed, no frenum. Total caudal-fin rays (including procurrent rays) 30 (holotype) or 31 (cleared and stained paratype; can't assess number from radiographs of other paratypes); segmented caudal rays 17; branched caudal rays12 (6+6); unbranched caudal rays 18 in holotype $(9+9), 19(10+9)$ in cleared and stained paratype. Dorsal-fin formula 3-22110. Vertebrae 10 precaudal +16 caudal. Epineurals 10 pairs. Ribs on vertebrae 3-10. Anal-fin pterygiophores anterior to first haemal spine 2. Gill rakers on first arch, including rudiments, $2+8$ (holotype and adult paratypes), $0+8$ in cleared and stained juvenile paratype. Branchiostegal rays 5 . Numerous scales abraded and missing on all specimens, one paratype with approximately 22 scales in longitudinal series, 6 scales between origin of second dorsal fin obliquely downward to anal fin, and approximately 17 circum-peduncular scales.

Measurements of holotype in parentheses following extremes for holotype plus two adult paratypes. Juvenile paratype bent and not measured prior to clearing and staining. Body elongate, maximum depth from base of dorsal-fin spines 17-19\% SL (17); body compressed, greatest width just posterior to gill opening $14-15 \%$ SL (14); head length $30-32 \%$ SL (32); snout length (to fleshy edge of orbit) $6.0-7.1 \%$ SL (6.0); greatest fleshy orbit diameter 9.3-10\% SL (9.3); least fleshy interorbital 1.3-3.3\% SL (3.3); caudal-peduncle length $23-24 \%$ SL (23); least caudal-peduncle depth $11-12 \%$ SL (11); length of dorsal-fin base 39-46\% SL (46); first dorsal spine 14-16\% SL (16); second dorsal spine 15-18\% SL (17); third and longest dorsal spine 16-20\% SL (18); sixth and shortest dorsal spine 7.0-8.4\% SL (8.4); seventh dorsal spine (first element of second dorsal fin) $14-16 \%$ SL (16); last dorsal soft ray 16-17\% SL (16); anal-fin spine $8.7-11 \%$ SL (11); last anal soft ray $20-22 \%$ SL (20); pectoral fin $32-36 \%$ SL (36), fin reaching vertical through second anal-fin soft ray, longest pectoral rays the $11^{\text {th }}-14^{\text {th }}$ rays from top of fin; pelvic fin $24-32 \%$ SL (27), fin reaching origin of anal fin or terminating slightly before origin, longest pelvic ray the fourth.

Trunk, belly, and pre-pelvic region scaled, head and predorsal region naked; scales ctenoid except on pre-pelvic region, where they are cycloid. Upper jaw with several rows of small conical teeth, outermost teeth largest but smaller than outermost dentary teeth; dentary with outer row of fairly large conical teeth and several inner rows of smaller teeth; innermost teeth intermediate in size between teeth of outermost row and those adjacent to it. No teeth on vomer, palatines, or pterygoids. Anterior nare opening on short tube; posterior nare a simple opening. Head pores prominent: nasal pore, anterior interorbital pore, posterior interorbital pore, infraorbital pore, postorbital pore, pore at each end of lateral sensory canal, pore at each end of posterior lateral canal, and three preopercular pores (pores B', C and D [both single], E, F, G, H', K', L', M', N, O'). A very low, thin ridge of tissue extending from just posterior to interobital region to base of first dorsal fin.

When photographed against a light background (Fig. 2A), the following color pattern visible in holotype. TRUNK: ground color white, several irregular horizontal rows of yellow/orange irregular-shaped blotches, most blotches bordered by and peppered with small black melanophores; uppermost row comprising approximately 11 blotches distributed along dorsal body margin from head (with two-three blotches) to caudal 

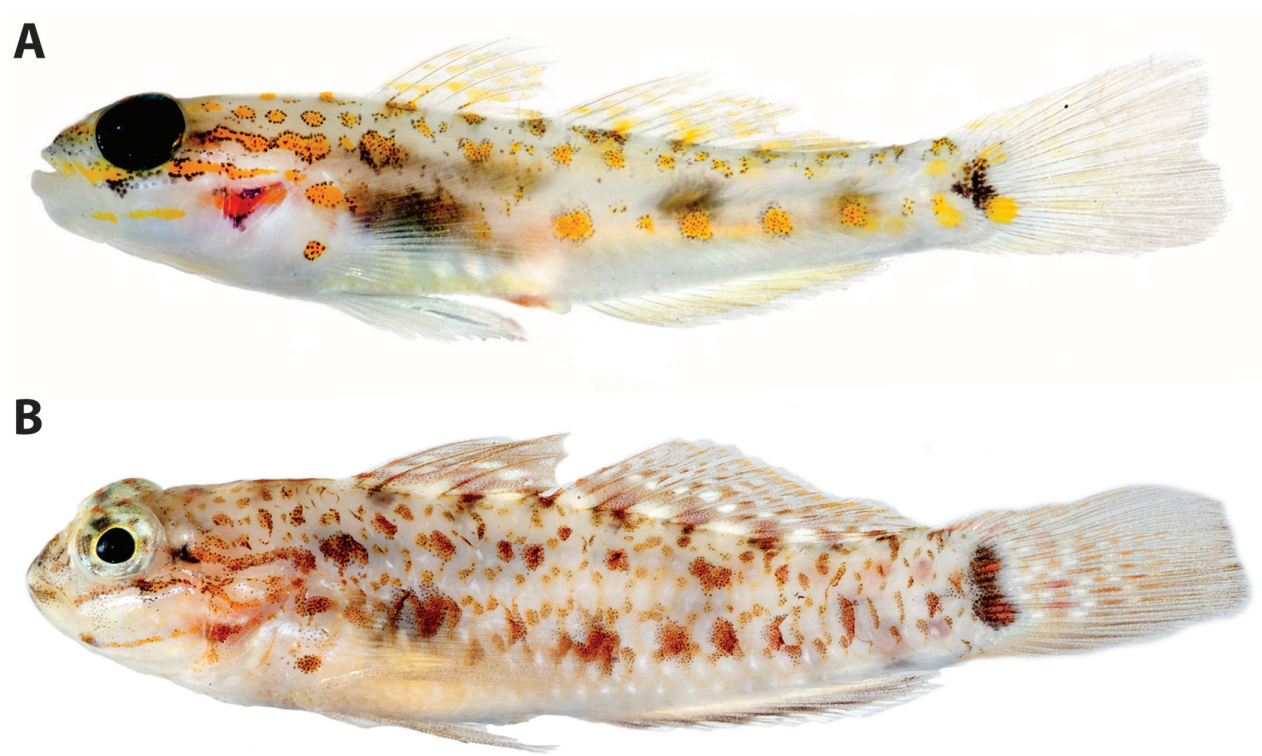

Figure 2. Comparison of A Coryphopterus curasub sp. n., holotype, USNM 406373, $33.3 \mathrm{~mm} \mathrm{SL}$, and its most similar congener B Coryphopterus dicrus, USNM 413296, $30 \mathrm{~mm}$ SL. Note the differences in the shape of the basicaudal pigment marking (with distinct anterior projection in C. curasub), body depth (shallower in C. curasub), head pigment (absence of a distinct blotch of black pigment immediately posterior to the orbit and presence of a black triangle of pigment beneath the anteroventral portion of orbit in C. curasub (present and absent, respectively, in C. dicrus), and trunk pigment (blotches predominantly yellow with few melanophores interspersed among them in C. curasub vs. blotches predominantly orange/ rust with numerous melanophores interspersed among them in $C$. dicrus).

peduncle; second row shortest, comprising approximately eight blotches and extending from just posterior to posterodorsal margin of orbit to vertical through third or fourth dorsal-fin spine; third row comprising approximately 15 blotches and extending from middle of posterior margin of orbit to caudal peduncle-anterior blotches of this row united to form irregular stripe; lowermost row comprising five prominent blotches that extend from vertical through anterior origin of second dorsal fin to posterior portion of caudal peduncle and several less conspicuous blotches anterior of and within this series; this row continuing anteriorly onto pectoral-fin base and head as an irregular yellow stripe that passes along ventral margin of orbit and terminates on posterior end of upper jaw; yellow blotches on anterior portion of trunk and head better defined by peripheral melanophores than those on posterior portion of trunk; scattered small spots of yellow/black pigment interspersed among blotches in most rows. HEAD: head pigment also including short yellow/black stripe on snout; yellow stripe on ventral portion of head from posterior end of lower jaw to preopercle; triangle of black pigment beneath anteroventral margin of orbit; scattered black dots on upper lip, on snout, and beneath eye; two small black blotches of pigment on operculum; some whitish pigment extending posterodorsally from dark triangle beneath orbit; pu- 
pil black, iris brown; ventral portions of head and trunk mostly white except for streak of yellow pigment beneath opercular opening. CAUDAL PEDUNCLE: dark crossshaped basicaudal blotch present on central portion of caudal peduncle and caudal-fin base, the anterior projection of cross prominent; two yellow spots bordering dorsal and ventral ends of blotch posteriorly and extending onto bases of several caudal-fin rays. FINS: first dorsal fin translucent, with three irregular yellow stripes; second dorsal fin with three or four irregular yellow stripes; anal fin with broad stripe of pale yellow pigment on middle of fin; caudal fin with blotches of yellow pigment forming an arc on basal portion of fin, some of this pigment extending distally along caudal rays as barely noticeable yellow streaks; pectoral and pelvic fins mostly clear; yellow/black blotch on dorsal portion of pectoral-fin base extending onto basal portion of dorsalmost pectoral rays; lower portion of pectoral-fin base with well-defined, round, yellow/orange blotch with dark dots. When photographed against a black background (Fig. 1B), numerous small, white, round to oblong spots visible on membranes of all fins; distal margin of anal fin with pale blue stripe.

Male paratypes (Fig. 1C) with similar coloration except black triangle of pigment beneath anteroventral corner of eye less conspicuous; melanophores present on lower jaw; iris mottled whitish/bronze; pectoral fin with pale yellow pigment; and pelvic fin with black-spotted yellow patches. IMMATURE SPECIMEN (Fig. 1D) paler but with most pigment described above developing; diagnostic cross-shaped marking on caudal peduncle not formed, and only lower black-spotted yellow blotch on pectoralfin base well formed; most prominent pigment comprising yellow stripes on head, five black-spotted yellow blotches on trunk in lowermost row, and black-spotted yellow blotch in line with this row on base of caudal fin.

Color of holotype in alcohol (Fig. 1A). Ground color of head and trunk light tan, overlain by assorted dark circles, stripes, and irregular markings. Scattered melanophores and blotches present along base of spinous dorsal fin and on dorsal portion of trunk. Most prominent trunk pigment located just ventral to lateral midline as a row of six mostly circular blotches of roughly equal size except the second from anterior and last, which are small relative to the others; this row of pigment markings originating at a vertical through second element of second dorsal fin and terminating on caudal peduncle. Head with several circular blotches in row posterior to posterodorsal portion of orbit; irregular stripe of pigment extending posteriorly from middle of orbit; irregular stripe-like mark extending posteriorly from posteroventral portion of orbit; scattered melanophores on snout, lacrimal, and upper jaw; dark triangle of pigment beneath anteroventral corner of orbit; and two irregular streaks of pigment on ventral portion of operculum. Dark portion of basicaudal blotch as described above, but no melanophores present on remainder of caudal fin or on anal and pelvic fins. First dorsal fin with small bits of dark pigment on membranes of second, third and fifth spines. Pectoral-fin base with one dorsal and one ventral circular blotches, the former extending as short series of melanophores posteriorly onto bases of dorsal rays of fin. 
Distribution. Known from 70-80 m off Curaçao, southern Caribbean.

Habitat. Notes recorded during the submersible dive on which the $33.0 \mathrm{~mm}$ SL paratype (USNM 431328) was collected indicate that it occurred on sand with rubble patches on a $45^{\circ}$ slope.

Etymology. Named for the manned submersible Curasub, which is owned and operated by Substation Curaçao, in recognition of the contributions of this vehicle to increasing our knowledge of the Caribbean deep-reef fish fauna.

Common name. "Yellow-spotted sand goby" refers to the yellow spots on the trunk and the collection habitat.

Morphological comparisons. Coryphopterus curasub is most similar to C. dicrus (Fig. 2) and keys to that species in the most recent dichotomous key to western Atlantic Coryphopterus (Baldwin et al. 2009). They share the presence of two dark circular markings on the pectoral-fin base that are of roughly equal intensity (except in the juvenile C. curasub, in which only the lower spot is prominent), the absence of a distinct black blotch or triangle of pigment behind the eye above the opercle in adults, the presence of a united pelvic fin in which the fourth rays are longer than the fifth, and the absence of a pelvic frenum. They usually differ in total number of rays (spinous plus soft) in the second dorsal fin (10-11, usually 11, in C. curasub, 10 in C. dicrus); absence of a dark triangular blotch immediately posterior to the orbit in C. curasub (present in $C$. dicrus); presence of a dark triangular blotch beneath the anteroventral portion of the orbit in the largest specimen (33.3 mm SL holotype) of C. curasub (absent in similarly large specimens of $C$. dicrus); blotches of pigment on the trunk typically yellow in C. curasub, orange to rusty brown in $C$. dicrus; few yellow spots with tiny melanophores among the yellow blotches of pigment on the trunk in C. curasub vs. many rusty spots with tiny melanophores between the rusty brown blotches in $C$. dicrus; configuration of the basicaudal blotch (a cross-shaped blotch with a distinct anterior projection in C. curasub vs. a dumbbell-shaped bar in C. dicrus); the two yellow/ orange blotches on the base of the caudal fin situated immediately behind the basicaudal blotch in C. curasub vs. superimposed on and contributing to the upper and lower heads of the basicaudal bar of $C$. dicrus; maximum body depth from base of spinous dorsal fin (17-19\% SL in C. curasub, 20-26\% SL in C. dicrus - Böhlke and Robins 1960); least depth of caudal peduncle (11-12\% SL in C. curasub, 13-15\% SL in C. dicrus - Böhlke and Robins 1960). Coryphopterus curasub differs from all other western Atlantic Coryphopterus (C. alloides Böhlke \& Robins, C. eidolon, C. glaucofraenum, C. hyalinus, C. kuna, C. lipernes, C. personatus, C. punctipectophorus, C. thrix, C. tortugae, and C. venezuelae) in having two round dark marks on the pectoral-fin base that are of roughly equal intensity in adults. It further differs from $C$. hyalinus, $C$. lipernes, and $C$. personatus in lacking a black ring around the anus; from those species and $C$. alloides in having the pelvic fin united; from C. glaucofraenum, $C$. tortugae, and C. venezuelae in lacking both a pelvic frenum and a distinct black blotch or triangle behind the eye above the opercle; and from C. kuna in having 10 or 11 total second dorsal-fin rays, 10 total anal-fin rays, and 19-20 pectoral-fin rays (vs. 9, 9, and 15, respectively). 
Of the 14 apomorphic morphological characters of Coryphopterus species tabulated by Thacker and Cole (2002) for inclusion in their phylogenetic analysis of the genus, C. curasub has (character 1) no pelvic frenum, (3) the fifth (innermost) pelvic-fin ray shortened relative to the fourth, (4) a low ridge of tissue on top of the head, (8) orange or gold coloration on the body, and (10) three stripes of pigment on the head. The presence of a low ridge of tissue on the head characterizes all Coryphopterus species and is thus uninformative. Likewise, although Thacker and Cole (2002) scored most species as lacking orange or gold coloration, in a more thorough analysis of fresh color patterns in western Atlantic Coryphopterus, Baldwin et al. (2009) noted the presence of yellow/orange/gold pigment in all species. Coryphopterus curasub shares with $C$. dicrus, $C$. alloides, $C$. personatus, $C$. hyalinus, and $C$. lipernes the absence of a pelvic frenum, with those taxa and $C$. eidolon a shortened fifth pelvic-fin ray (relative to the fourth), and with C. eidolon, $C$. thrix, C. dicrus, C. glaucofraenum, C. tortugae, C. venezuelae, C. urospilus, and C. punctipectophorus the presence of three stripes of pigment on the head. In C. curasub, the lowermost stripe (on the cheek) is yellow and lacks melanophores, which are present in the other species. The homology of the pigment stripes is thus questionable. Thacker and Cole (2002) list several apomorphic characters (11-13) related to basicaudal pigment, but the configuration of the basicaudal blotch in C. curasub is unique among Coryphopterus species. Thacker and Cole's (2002) $14^{\text {th }}$ character, the presence or absence of a pigment spot on the pectoral-fin base, insufficiently describes the variation in this character in Coryphopterus. Of the various configurations-no spots, one spot dorsally, one spot ventrally, two spots with upper spot more intense, two spots of roughly equal intensity-only C. curasub and C. dicrus have two spots of equal intensity among Coryphopterus species and outgroup taxa. In summary, of the potentially informative, putative apomorphic characters exhibited by C. curasub, only $C$. dicrus shares all of them.

Genetic comparisons. COI sequences derived from tissue samples from the four type specimens of $C$. curasub and three specimens of $C$. venezuelae collected by submersible as part of this study (Appendix) were combined with 173 previously published COI sequences for western Atlantic Coryphopterus (Baldwin et al. 2009, Weigt et al. 2012b) in a neighbor-joining analysis (Fig. 3). Intraspecific divergence in COI for C. curasub was $0.1 \%$ as compared to $17-23 \%$ interspecific divergence between C. curasub and other western Atlantic Coryphopterus species, including C. dicrus (18\%, Table 1). Intraspecific divergences for all western Atlantic Coryphopterus species were $<1 \%$ except for $C$. alloides (3.7\%), likely reflecting, as suggested by Baldwin et al. (2009), a cryptic species that awaits investigation. Phylogenetic relationships within Coryphopterus were analyzed using a reduced COI dataset of western Atlantic Coryphopterus (43 ingroup sequences selected from the entire COI data set to maximize geographical coverage of each species), the eastern Pacific $C$. urospilus, and the western Atlantic Lophogobius cyprinoides. A strict consensus of 24 trees resulting from a maximum parsimony analysis (Fig. 4) does not resolve the 


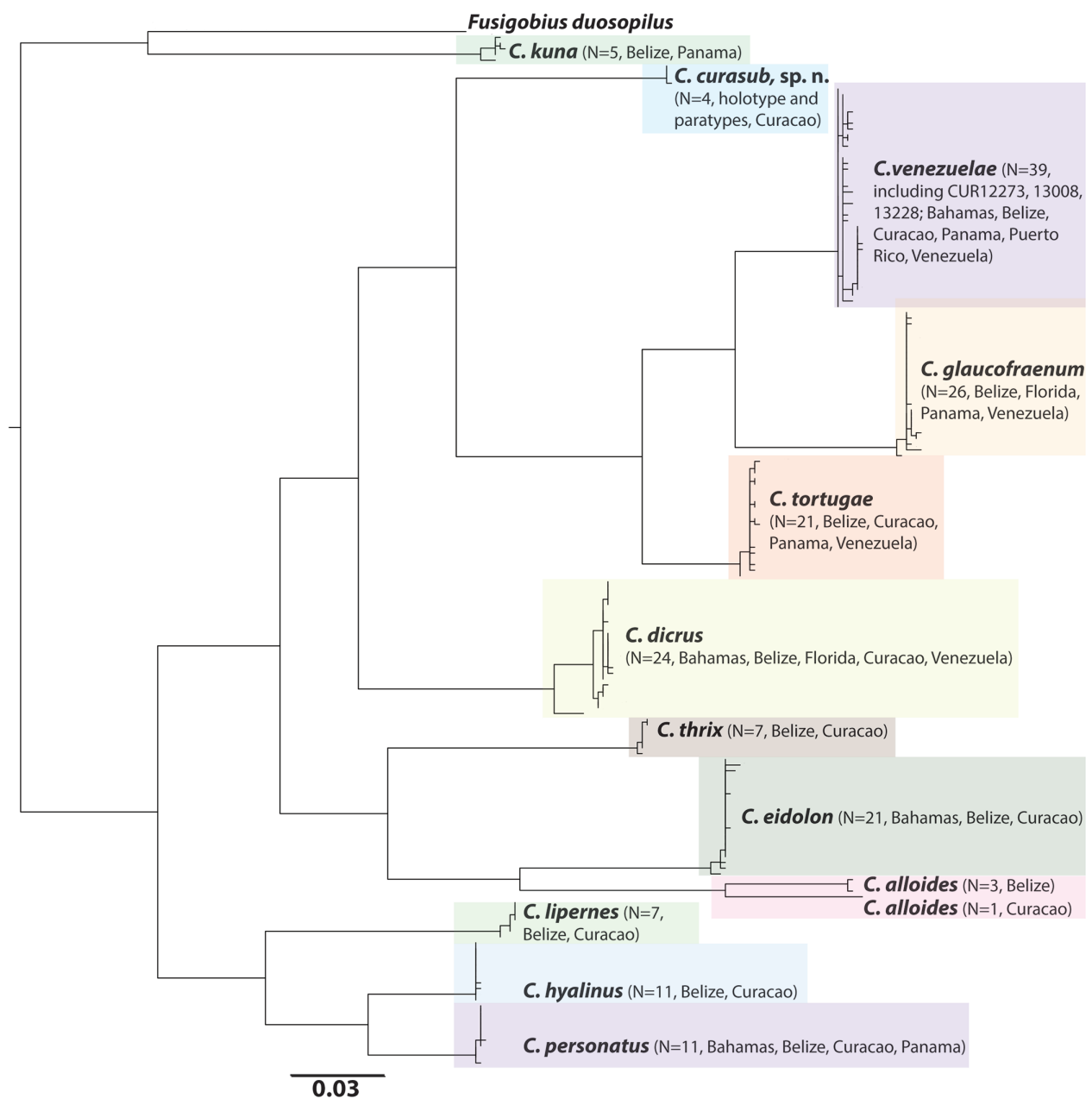

Figure 3. Neighbor-joining tree derived from COI sequences for western Atlantic species of Coryphopterus. The tree was rooted on Fusigobius duospilus. Divergence represented by scale bar $=3 \%$. Note: $C$. punctipectophorus from the Gulf of Mexico was not available for inclusion in this analysis.

relationships of C. curasub with confidence. A clade comprising C. venezuelae, $C$. glaucofraenum, and C. tortugae is strongly supported (99\%), as are clades comprising C. venezuelae and C. glaucofraenum (80\%), the hovering species C. hyalinus and C. personatus $(100 \%)$, and the planktivores C. lipernes $+C$. hyalinus $+C$. personatus (63\%). As noted by Thacker and Cole (2002) based on ND2 mitochondrial and morphological data, Lophogobius is closely related to Coryphopterus, here appearing in a poorly supported clade that also comprises $C$. dicrus and the eastern Pacific $C$. urospilus. Adding more loci to the genetic analysis as well as C. punctipectophorus and the eastern- and Indo-Pacific species of Lophogobius may help resolve interspecific 


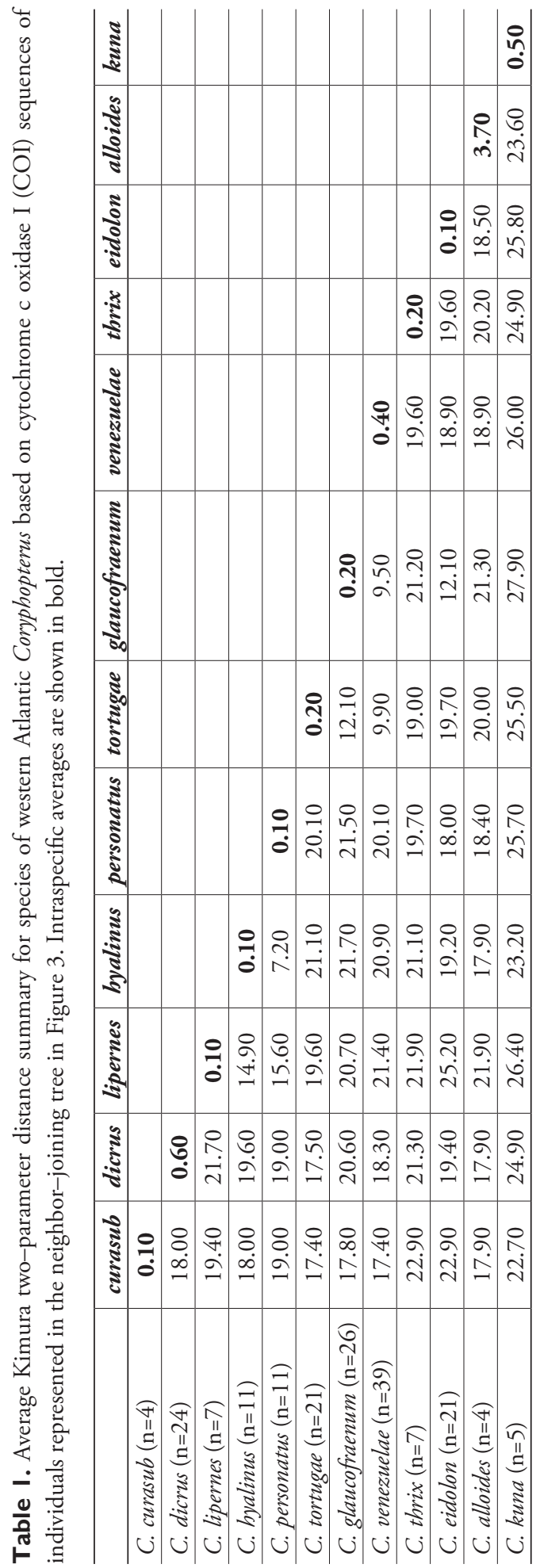




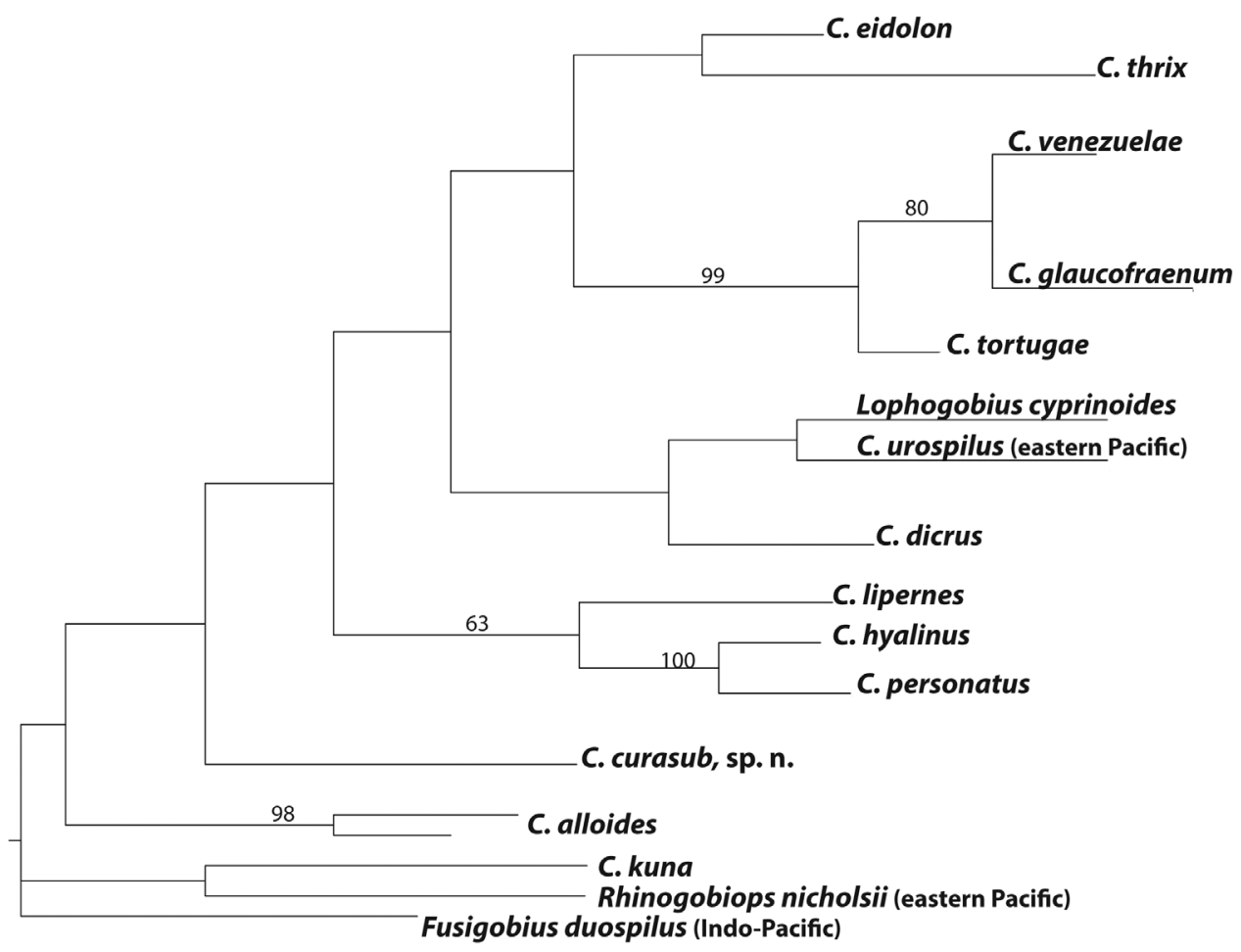

Figure 4. The strict consensus of a maximum parsimony analysis of the COI region of 42 individuals of Coryphopterus and Lophogobius cyprinoides. Fusigobius duospilus and Rhinogobiops nicholsii were outgroups in the analysis. Numbers above branches represent bootstrap support values $>50$. Note: $C$. punctipectophorus from the Gulf of Mexico was not available for inclusion in this analysis.

and generic relationships. The placement of C. kuna outside of the western Atlantic Coryphopterus + Lophogobius cyprinoides clade warrants further morphological and molecular investigation.

Depth distributions. Depth ranges of Coryphopterus species are shown in Figure 5. Coryphopterus curasub, which is known from $70-80 \mathrm{~m}$, is the only member of the genus that has a narrow depth range completely confined to mesophotic depths. Coryphopterus venezuelae, C. glaucofraenum, C. dicrus, C. eidolon, C. thrix, C. hyalinus, C. lipernes, and C. personatus inhabit depths as deep as 52-70 $\mathrm{m}$, but they have broad depth ranges that extend as shallow as 1-6 m. The only Coryphopterus species in addition to C. curasub that we have collected using the Curasub submersible are C. hyalinus - one specimen from $33 \mathrm{~m}$, and C. venezuelae - three specimens from 65-69 m. Prior to this study, C. venezuelae was known from 1-20 m (Robertson and Van Tassell 2015), and thus our new collections of the species off Curacao extend its known range by nearly $50 \mathrm{~m}$. 


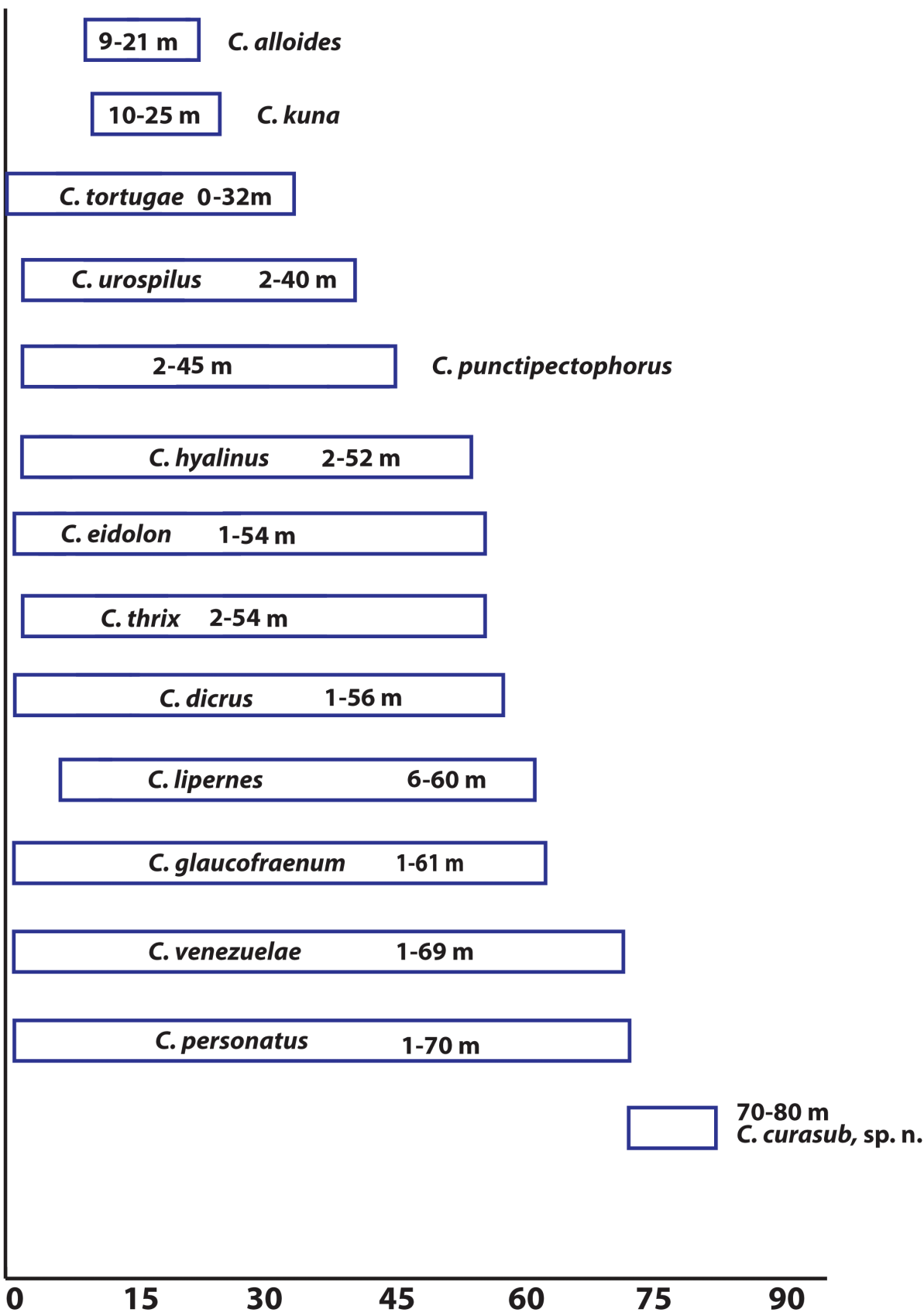

Figure 5. Depth ranges for Coryphopterus species. Data are from Böhlke and Robins (1960, 1962); Thacker and Cole (2002); Feitoza et al. (2005); Robertson and Van Tassell (2015); the Florida Museum of Natural History online fish catalog - http://specifyportal.flmnh.ufl.edu/fishes/; the Florida Fish and Wildlife Conservation Commission online catalog http://myfwc.com/research/saltwater/specimen-collections/sis/ichthyology/; the Smithsonian National Museum of Natural History online catalog - www. vertebrates.si.edu//search/fishes); and this study. 


\section{Revised key to the Western Atlantic species of Coryphopterus}

(Modified from Baldwin et al. 2009)

$1 \quad$ Black ring surrounding anus; pelvic fins separate, frenum absent ................ 2

- $\quad$ No black ring around anus; pelvic fins separate or fused, frenum present or

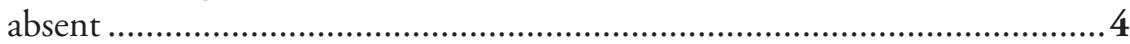

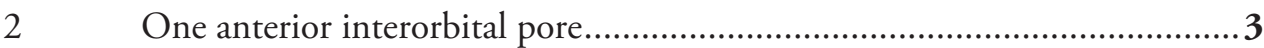

- Two anterior interorbital pores ................................. Coryphopterus hyalinus

3 Total second dorsal-fin rays (spinous plus soft) typically 11; total anal-fin rays (spinous plus soft) typically 11 ; in life, head with orange pigment, body translucent with several square- or rectangular-shaped orange blotches internally; preserved specimens lacking conspicuous postorbital stripes of melanophores but with dark "mask" around eye ............ Coryphopterus personatus

- $\quad$ Total second dorsal-fin rays (spinous plus soft) typically 10; total anal-fin rays (spinous plus soft) typically 10 ; in life, head and body predominantly yellow, with blue-white stripes extending posteriorly from dorsal and ventral portions of orbit; a dusky internal stripe along posterior section of vertebral column; preserved specimens with postorbital stripes of melanophores and scattered spots over entire body.

Coryphopterus lipernes

$4 \quad$ No distinct black blotch behind eye above opercle in adults; pigment mark above opercle, if present, no larger or darker than other marks behind eye; pelvic fins separate or fused, frenum present or absent (see Baldwin et al. 2009 for additional comments)................................................................

- $\quad$ Distinct black blotch or triangle behind eye above opercle in adults, blotch usually larger and darker than other pigment in stripe behind eye; pelvic fins fused to form disc, frenum present (see Baldwin et al. 2009 for additional

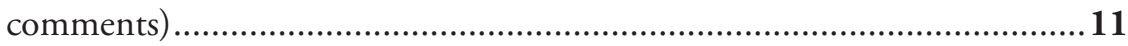

$5 \quad$ Total anal-fin rays (spinous plus soft) 8-9 (usually 9), pectoral-fin rays 1517, pelvic fins separate or fused, frenum absent..........................................6

- $\quad$ Total anal-fin rays (spinous plus soft) 10-11, pectoral-fin rays 17-20, pelvic fins fused, frenum present or absent.........................................................

6 Total second dorsal-fin rays (spinous plus soft) 9; total anal-fin rays (spinous plus soft) 9; pectoral-fin rays 15; first dorsal fin with stripe of black pigment; in life, head and body with orange spots and blotches, sometimes a flag of dark pigment on 1st-3rd dorsal spines; pelvic fins fused to form a disc.... Coryphopterus kuna

- $\quad$ Total second dorsal-fin rays (spinous plus soft) 10; total anal-fin rays (spinous plus soft) 9 (rarely 8); pectoral-fin rays 16-17; black blotch or bar between 2nd and 3rd dorsal spines; in life, head and anterior portion of body mottled orange, posterior portion of body mottled yellow; pelvic fins separate

Coryphopterus alloides

Pectoral-fin base with two prominent dark spots of equal intensity, one dorsally and one ventrally; upper spot usually with swath of melanophores 
extending posteriorly onto pectoral-fin rays; sides of body freckled with scattered large and small blotches of melanophores (blotches associated with orange, rust, or yellow pigment in life); pelvic frenum absent .................... 8

- $\quad$ Pectoral-fin base with or without two prominent dark spots; if two spots present, upper spot more intense; sides of body with few dark markings (with few to many yellow spots in life) or with three rows of light markings (coral pink/orange in life); pelvic frenum present.

Total second dorsal-fin rays (spinous plus soft) 10; a dark triangle immediately behind orbit; no dark triangle under front of orbit; basicaudal mark a vertical dumbbell that in life incorporates two large orange spots on the base of the caudal fin; maximum body depth beneath spinous dorsal fin 20-26\% SL, least depth of caudal peduncle $13-15 \% \mathrm{SL}$, depth range $0-56 \mathrm{~m}$

Coryphopterus dicrus Total second dorsal-fin rays (spinous plus soft) 10 or 11, usually 11; no dark triangle behind orbit; dark triangle variously developed beneath front part of orbit; basicaudal blotch cross-shaped, the anterior horizontal projection prominent; in life, two large yellow spots on base of caudal fin just posterior to basicaudal blotch; maximum body depth beneath spinous dorsal fin 17-19\% SL; least depth of caudal peduncle 9-12\% SL; depth range 70-80 $\mathrm{m}$

Coryphopterus curasub sp. $\mathrm{n}$.

9 Pectoral-fin base without prominent dark markings, but may have scattered melanophores; sides of body with few if any dark markings (with yellow to orange spots and stripes in life) except for several dark streaks internally along spinal cord and a thin dark basicaudal bar.

Coryphopterus eidolon Pectoral-fin base with prominent markings; sides of body with or without numerous dark markings

10 Pectoral-fin base with distinct, often large, pigment spot dorsally, spot usually dark above, diffuse below, often with dots trailing ventrally; ventral dots coalescing into a separate spot in some specimens (ventral spot, if present, less intense than dorsal spot); total second dorsal-fin rays (spinous plus soft) 9-10; second dorsal spine filamentous; in life, first dorsal fin without orange stripes

Coryphopterus thrix

- $\quad$ Pectoral-fin base with prominent dark spot or blotch ventrally; total second dorsal-fin rays (spinous plus soft) 11; second dorsal spine not filamentous; in life, first dorsal fin with two broad orange stripes

\section{Coryphopterus punctipectophorus}

11 Body usually pale, pigment primarily comprising three rows of markings on side of body; lower row comprising small, mostly vertically elongate markings, some of which may be crescent shaped or some part of an X-shape but rarely well-defined X's; height of any X-shaped markings considerably less than eye diameter; pigment mark above opercle usually a triangle, and basicaudal pigment usually a central bar

Coryphopterus tortugae

- $\quad$ Body heavily pigmented or pale but no vertically elongate or crescent-shaped markings in ventral row of pigment on side of body; height of any X-shaped 
markings three-quarters of or equal to eye diameter; pigment mark above opercle triangular, rounded, or with two peaks; basicaudal pigment variable: two separate spots, a vertical dumbbell, a central bar, or a C-shaped marking..... 12 Pectoral-fin base with dark spot or rectangle ventrally (may be associated with bright yellow pigment in life); one or two bars or blotches sometimes present dorsally; three rows of dark markings on side of body, some in lower row large, X-shaped markings in heavily pigmented specimens, small, circular blotches in paler specimens; pigment mark above opercle triangular or round Coryphopterus venezuelae

- $\quad$ Pectoral-fin base rarely with prominent dark marking ventrally (may have one to three light to moderate concentrations of melanophores); body with three rows of dark marks, most of those in the lower row large and distinctively X-shaped; pigment mark above opercle usually with two well-defined peaks

Coryphopterus glaucofraenum

\section{Discussion and conclusions}

Exploratory submersible diving to $300 \mathrm{~m}$ off Curaçao is resulting in the discovery of numerous new fish species, only a few of which have been described to date (Baldwin and Robertson 2013, 2014; Baldwin and Johnson 2014). In addition to the new Coryphopterus described here, numerous seven-spined gobies that represent undescribed species in the Chriolepis/Psilotris/Varicus group have been collected, as have several new species of Lythrypnus-like gobies and a putative new species of Palatagobius. A new genus and species of deep-reef goby, Antilligobius nikkiae Van Tassell, Tornabene, and Colin, was recently described from deep reefs at several localities in the Caribbean (including Curaçao) and Bahamas (Van Tassell et al. 2012). Deep-reef fish faunas in general have been poorly studied globally, and the recent new-species discoveries suggest that our knowledge of the deep-reef gobiid fauna in the southern Caribbean, and likely circumglobally, is far from complete. One question of interest is whether deepreef species generally represent single offshoots of largely shallow-reef clades or form natural evolutionary groups. Antilligobius nikkiae, which inhabits depths of 73-150 m, appears to have its closest relative in shallower water than it inhabits. Rüber et al. (2003) hypothesized that Antilligobius belongs within the monophyletic Microgobius group of the tribe Gobiosomatini, specifically as the sister group of the monophyletic Microgobius. Tornabene et al. (2012) tabulated depth distributions for Microgobius species, which occur from $<1 \mathrm{~m}$ to at least $75 \mathrm{~m}$, but most occur at depths $<20 \mathrm{~m}$. The COI data analyzed in this study do not rigorously resolve relationships among Coryphopterus species, but morphological data suggest that $C$. curasub may be most closely related to $C$. dicrus. Depth ranges of those species (1-56 m for C. dicrus, $70-80 \mathrm{~m}$ for C. curasub) do not overlap, suggesting that if they are sister species, depth-mediated speciation may have been involved in their evolution. Additional morphological and genetic analyses of Coryphopterus and other goby genera are in progress in efforts to 
investigate patterns of speciation and historical invasions of deep tropical reefs. Filling gaps in our knowledge of deep-reef species diversity is critical to meaningful hypotheses about the evolution of the deep-reef fauna, and we therefore continue to seek funding for exploratory diving aboard the Curasub.

\section{Acknowledgments}

For contributing in various ways to this project, we thank the following (in alphabetical order): Bruce Brandt, Barry Brown, Cristina Castillo, Amy Driskell, Tico Christiaan, Rob Loendersloot, Dan Mulcahy, Diane Pitassy, Sandra Raredon, Laureen Schenk, Adriaan Schrier, Ian Silver-Gorges, Jennifer Strotman, Laura Tancredi, Barbara van Bebber, and Lee Weigt. Funding for the Smithsonian Institution's Deep Reef Observation Project was provided internally by the Consortium for Understanding and Sustaining a Biodiverse Planet to CCB, the Competitive Grants for the Promotion of Science program to CCB and DRR, and the Herbert R. and Evelyn Axelrod Endowment Fund for systematic ichthyology to CCB; and externally by National Geographic Society's Committee for Research and Exploration to CCB (Grant \#9102-12). This is Ocean Heritage Foundation/Curacao Sea Aquarium/Substation Curacao (OHF/SCA/ SC) contribution number 17.

\section{References}

Akihito P, Hayashi M, Yoshino T (1988) Suborder Gobioidei. In: Masuda K, Amaoka C, Araga C, Uyeno Y, Yoshino T (Eds) The Fishes of the Japanese Archipelago. Tokai University Press, Tokyo.

Baldwin CC, Johnson GD (2014) Connectivity across the Caribbean Sea: DNA barcoding and morphology unite an enigmatic fish larva from the Florida Straits with a new species of sea bass from deep reefs off Curaçao. PLoS ONE 9(5): e97661. doi: 10.1371/journal. pone.0097661

Baldwin CC, Robertson DR (2013) A new Haptoclinus blenny (Teleostei, Labrisomidae) from deep reefs off Curacao, southern Caribbean, with comments on relationships of the genus. ZooKeys 306: 71-81. doi: 10.3897/zookeys.306.5198

Baldwin CC, Robertson RD (2014) A new Liopropoma sea bass (Serranidae, Epinephelinae, Liopropomini) from deep reefs off Curaçao, southern Caribbean, with comments on depth distributions of western Atlantic liopropomins. ZooKeys 409: 71-92. doi: 10.3897/ zookeys.409.7249

Baldwin CC, Weigt LA, Smith DG, Mounts JH (2009) Reconciling genetic lineages with species in western Atlantic Coryphopterus (Teleostei: Gobiidae). In: Lang MA et al. (Eds) Proceedings of the Smithsonian Marine Science Network Symposium. Smithsonian Contributions to the Marine Sciences 38: 113-140. 
Baldwin CC, Weigt LA (2012) A new species of soapfish (Teleostei: Serranidae: Rypticus), with redescription of $R$. subbifrenatus and comments on the use of DNA barcoding in systematic studies. Copeia 2012: 23-36. doi: 10.1643/CG-11-035

Birdson RS, Murdy EO, Pezold FL (1988) A study of the vertebral column and median fin osteology in gobioid fishes with comments on gobioid relationships. Bulletin of Marine Science 42: 174-214.

Böhlke JE, Robins CR (1960) A revision of the gobioid fish genus Coryphopterus. Proceedings of the Academy of Natural Sciences of Philadelphia 112: 103-128.

Lea I (1962) The taxonomic position of the west Atlantic goby, Eviota personata, with descriptions of two new related species. Proceedings of the Academy of Natural Sciences of Philadelphia 14: 175-189.

Chakrabarty P, Warren M, Page LM, Baldwin CC (2013) GenSeq: An updated nomenclature and ranking for genetic sequences from type and non-type sources. ZooKeys 346: 29-41. doi: 10.3897/zookeys.346.5753

Feitoza BM, Rosa RS, Rocha LA (2005) Ecology and zoogeography of deep reef fishes in northeastern Brazil. Bulletin of Marine Science 76: 725-742.

Garzón-Ferreira J, Acero AP (1990) Redescription of Coryphopterus tortugae (Jordan) (Osteichthyes: Gobiidae), a valid species of goby from the western Atlantic. Northeast Gulf Science 11: 105-112.

Kimura M (1980) A simple method for estimating evolutionary rates of base substitutions through comparative studies of nucleotide sequences. Journal of Molecular Evolution 16: 111-120. doi: 10.1007/BF01731581

Longley WH, Hildebrand F (1941) Systematic Catalogue of the Fishes of Tortugas, Florida: With Observations on Color, Habits, and Local Distribution. Carnegie Institution of Washington, Washington, D.C., 331 pp.

Murdy EO (2002) Gobiidae. In: Carpenter KE (Ed.) The living marine resources of the western Central Atlantic. Bony Fishes, Part 2 (Opistognathidae to Molidae), Sea Turtles and Marine Mammals. The Food and Agriculture Organization of the United Nations, Rome 3: 1375-2127.

Randall JE (1995) Fusigobius Whitley, a junior synonym of the gobiid fish genus Coryphopterus Gill. Bulletin of Marine Science 56: 795-798.

Randall JE (2001) Five new Indo-Pacific gobiid fishes of the genus Coryphopterus. Zoological Studies 40: 206-225.

Robertson DR, Van Tassell J (2015) Shorefishes of the Greater Caribbean: online information system. Version 1.0 Smithsonian Tropical Research Institute, Balboa, Panamá.

Rüber L, Van Tassell JL, Zardoya R (2003) American seven-spined gobies (Gobiidae, Gobiosomatini) inferred from a molecular phylogeny. Evolution 57: 1584-1598. doi: 10.1111/ j.0014-3820.2003.tb00366.x

Saitou N, Nei M (1987) The neighbor-joining method: a new method for reconstructing phylogenetic trees. Molecular Biological Evolution 14: 406-425.

Swofford D (2002) PAUP*: phylogenetic analysis using parsimony (*and other methods). Sinauer Associates, Sunderland, Massachusetts. 
Thacker CE, Roje DM (2011) Phylogeny of Gobiidae and identification of gobiid lineages. Systematics and Biodiversity 9: 329-347. doi: 10.1080/14772000.2011.629011

Thacker CE, Cole KS (2002) Phylogeny and evolution of the gobiid genus Coryphopterus. Bulletin of Marine Science 70: 837-850.

Tornabene L, Van Tassell JL, Robertson DR (2012) Microgobius urraca (Teleostei: Gobiidae), a new species of goby from the tropical eastern Pacific. Zootaxa 3447: 41-55.

Van Tassell JL (2011) Gobiiformes of the Americas. In: Patzner RA et al. (Eds) The Biology of Gobies. CRC Press, Science Publishers 2.1: 139-176. doi: 10.1201/b11397-14

Van Tassell JL, Tornabene L, Colin PL (2012) Review of the western Atlantic species of Bollmannia (Teleostei: Gobiidae: Gobiosomatini) with the description of a new allied genus and species. Aqua 18: 61-94.

Victor BC (2007) Coryphopterus kuna, a new goby (Perciformes: Gobiidae: Gobiinae) from the western Caribbean, with the identification of the late larval stage and an estimate of the pelagic larval duration. Zootaxa 1526: 51-61.

Victor BC (2008) Redescription of Coryphopterus tortugae (Jordan) and a new allied species Coryphopterus bol (Perciformes: Gobiidae: Gobiinae) from the tropical western Atlantic Ocean. Journal of the Ocean Science Foundation 1: 1-19.

Weigt LA, Driskell AC, Baldwin CC, Ormos A (2012a) DNA barcoding fishes. Chapter 6 In: Kress WJ, Erickson DL (Eds) DNA Barcodes: Methods and Protocols, Methods in Molecular Biology 858: 109-126. doi: 10.1007/978-1-61779-591-6_6

Weigt LA, Baldwin CC, Driskell A, Smith DG, Ormos A, Reyier E (2012b) Using DNA barcoding to assess Caribbean reef fish biodiversity: expanding taxonomic and geographic coverage. PLoS ONE 7(7): e41059. doi: 10.1371/journal.pone.0041059

\section{Appendix}

Links between DNA voucher specimens, GenBank accession numbers, and cytochrome c oxidase subunit I (COI) sequences of Coryphopterus curasub sp. n. and C. venezuelae.

\begin{tabular}{l|l|c}
\hline Catalog Number/DNA Number & GenBank No. & GenSeq Designation \\
\hline Coryphopterus curasub sp. $\mathrm{n}$. & & \\
\hline USNM 406373, CUR 11373, Holotype & KT020955 & Geneseq-1 COI \\
\hline USNM 430037, CUR 13302, Paratype & KT020957 & Genseq-2 COI \\
\hline USNM 431328, CUR 14003, Paratype & KT020961 & Genseq-2 COI \\
\hline USNM 430019, CUR 13303, Paratype & KT020958 & Genseq-2 COI \\
\hline Coryphopterus venezuelae & & \\
\hline USNM 413804, CUR 12273 & KT020959 & Genseq-4 COI \\
\hline USNM 413992, CUR 13008 & KT020956 & Genseq-4 COI \\
\hline USNM 430016, CUR 13328 & KT020960 & Genseq-4 COI \\
\hline
\end{tabular}

